\title{
PEMBERDAYAAN GURU DI MADRASAH IBTIDAIYAH (MI) AL-IFADAH PENJARINGAN JAKARTA UTARA
}

\author{
Fatimah dan As'ad \\ Dosen Program Studi Pendidikan Bahasa dan Sastra Indonesia Universitas Indraprasta PGRI Jakarta \\ Email : fatimahifat4@gmail.com; asad.ptunu@gmail.com
}

\begin{abstract}
The objective of this research was to understand comprehensively the empowerment of teachers' at the Al-Ifadah Islamic secondary school it was a qualitative research with study case method conducted in Penjaringan, north Jakarta. In this research data collecting with triangulation technique to get credibility in this research grouped as (1) give longer time in research location (2) observation 60 documentation. After with the data categorized and coding were done in two data summary appropriately with the research problem and sub problems then and data analysis about completeness and relevance data examined. The finding lead to the recommendation teacher's for continues them studies to get more education to apply teachers' training in term of teacher's empowerment. Socialization leading and socialization training in order to get the Al-Ifadah Islamic secondary school running well, it is recommended for education head masters and teachers to improve accountability in assessing standard of Islamic secondary school.

Key word: teachers' empowerment, education, training.
\end{abstract}

\section{PENDAHULUAN}

Sekolah merupakan lembaga pendidikan yang dirancang untuk mencerdaskan kehidupan anak bangsa. Di sana diselenggarakan pembelajaran dengan segenap kelengkapan perangkatnya, seperti sarana dan prasarana, kegiatan terjadwal, seperangkat aturan, dan lain sebagainya. Tercapainyatujuan sekolahadalah menghasilkan manusia yang cerdas, mandiri, dan kompetitif, serta dapat berkontribusi terhadap pembangunan bangsa.

Pandangan pemerhati pendidikan terhadap maju mundurnya lembaga pendidikan selalu mengacu kepada stakeholders atau pelaku pendidikan..Pemerintah sebagai pemangku kebijakan pendidikan, kepala sekolah sebagai pemimpin lembaga pendidikan, guru sebagai ujung tombak proses pembelajaran, dan tenaga kependidikan sebagai perangkat sekolah.

Sebagai ujung tombak, kepala sekolah dan guru memiliki peran penting karena mereka adalah pelaksana program pendidikan di lembaganya..Dapat dilaksanakan atau tidaknya suatu program pendidikandan tercapai atau tidaknya tujuan pendidikan, sangat bergantung kepada kecakapan kepala sekolah dan guru.

Membangun kerja sama antara kepala sekolah dan guru merupakan hal yang mendasar. Guru adalah insan terdidik, intelektualitas, dan mempunyai arah pandang yang 
sistematis. Menjadi tanggung jawab bagi kepala sekolah untuk mengembangkan dan memberdayakan potensi-potensi tersebut sehingga tujuan sekolah dapat tercapai yaituoutput yang dihasilkan adalah siswa yang cerdas, inovatif, mandiri, kompetitif, teruji, dan siap bersaing di luar lingukungan sekolahnya.

Guru yang diberdayakan akan mampu menjalankan tugas, kewajiban, dan fungsinya secara profesional. Wujud pemberdayakan guru adalah dengan mengembangkan potensi-potensi yang mereka miliki, di antaranya memberikan kesempatan dan dukungan kepada mereka untuk melanjutkan jenjang pendidikan yang lebih tinggi, mengikutsertakan mereka dalam pelatihan, workshop, dan sejenisnya.

Implementasi pemberdayaan guru sebagaimana peneliti cermati di objek penelitian dalam hal ini adalah Madrasah Ibtidaiyah (MI) Al-Ifadah yang beralamat di Kelurahan dan Kecamatan Penjaringan Jakarta Utara.Pada pra observasi di sekolah tersebut, ada hal-hal yang menarik dan unik untuk diteliti. Dengan mengamati kondisi sekolah, dan lingkungan sekolah, banyak masalah-masalah yang ada di sekolah tersebut diantaranya kondisi sekolah dan lingkungan sekolah yang banyak keterbatasan seperti gedung sekolah menyatu dengan rumah penduduk, banjir saat hujan lebat, tidak adanya halaman sekolah, sarana dan prasarana sekolah jauh dari standar kelayakan jika dibandingkan dengan sekolah-sekolah setingkatnya, dan masih banyak yang lainya.

Namun ada hal yang menarik dari permasalahan yang komplek dan keterbatasan yang ada di sekolah tersebut. Hal-hal menarik tersebut adalah banyak prestasi yang diraih oleh siswa dan siswi MI Al-Ifadahdiantaranya sekolah tersebut peringkat 10 besar dari 64 sekolah se wilayah Jakarta Utara, juara II lomba cerdas cermat antar Madrasah se wilayah Jakarta Utara, Juara II lomba Sains Matematika dan IPA tingkat kecamatan Penjaringan (dari 19 sekolah), 70\% lulusan MI Al-Ifadah diterima, SMPN, seperti SMPN 21 Penjaringan, SMPN 32 Pekojan, dan 30\% meneruskan pendidikan di pondok pesantren serta sekolah swasta, dan masih banyak yang lainnya.

Peneliti semakin tertarik untuk mendalami penelitian. Dengan melakukan pengamatan dan mewawancarai Kepala Sekolah dan guru senior, peneliti dapat menyimpulkan bahwa sederet prestasi yang diraih oleh sekolah tersebut tidak lepas dari peran kepala sekolah dalam mengoptimalkan pemberdayaan guru. Adapun strategi yang dilakukan kepala sekolah dalam pemberdayaan guru di sekolah tersebut adalah adanya pelatihan terprogram dengan dua mekanisme, 1) pelatihan intern sekolah, pelatihan yang 
diselenggarakan di sekolah. 2)pelatihan ekstern sekolah, pelatihan yang diselenggarakan di luar sekolah.Di samping melalui program pelatihan, strategi lain yang diterapkan kepala sekolah dalam memberdayakan memberikan kesempatan kepada guru-guru untuk melanjutkan pendidikan ke jenjang yang lebih tinggi.

Berdasarkan uraian di atas, dapat disimpulkan bahwa pemberdayaan guru memiliki peran strategis dalm mewujudkan prestasi sekolah dan membangun kercerdasan anak bangsa yang sejahtera dan bermartabat.

\section{TINJAUAN PUSTAKA}

Dalam Kamus Besar Bahasa Indonesia (2003:212-213) dijelaskan bahwa pemberdayaan berasal dari kata “daya” yang berarti kesanggupan untuk berbuat, kemampuan untuk melakukan sesuatu atau kemampuan bertindak. Mendapat awalan “ber” menjadi “berdaya” artinya berkekuatan, berkemampuan, bertenaga, mempunyai akal (cara dan sebagainya) untuk mengatasi sesuatu. Mendapat awalan dan akhiran "pean” sehingga menajadi “pemberdayaan” yang dapat diartikan sebagai usaha atau proses menjadikan untuk membuat mampu, membuat dapat bertindak atau melakukan sesuatu

LIoyd L. Byars dan Leslie W. Rue (2008:9) berpendapat bahwa empowerment is a from of decentralization that involves giving subordinates substantial authority to make decisions. Menurut pendapat Raymond A. Noe dkk (2003:17) bahwa empowerment mean giving employees responsibility and authority to make decisions regarding all aspects of product development or customer service. Sedarmawanti(2007:285) berpendapat bahwa pemberdayaan secara umum diartikan lebih berdaya dari sebelumnya, baik dalam hal wewenang, tanggung jawab, maupun kemampuan individu yang dimilikinya.Menurut pendapat Suwatno dan Donni Juni Priansa (2011:189) bahwa pemberdayaan adalah suatu kegiatan untuk mengelola sumberdaya manusia lebih baik lagi.Kegiatan pemberdayaan bisa dilaksanakan dengan pengembangan kompetensi (competency), wewenang kepercayaan (confidence), wewenang (authority), dan tanggung jawab (responsibility) dalam rangka pelaksanaan kegiatan (activities) dalam rangka peningkatan kinerja (performance) sebagaimana diharapkan. Menurut pendapat para ahli di atas, dapat disimpulkan bahwa, pemberdayaan adalah proses usaha optimalisasi kemampuan, pengetahuan, sikap dan potensi yang dimiliki seseorang untuk dikembangkan agar dapat memiliki nilai manfaat yang lebih luas dan baik. Dengan membuat orang menjadi lebih 
berdaya atau lebih berkemampuan untuk menyelesaikan masalahnya sendiri, dengan cara memberikan kepercayaan dan wewenang, sehingga menumbuhkan rasa tanggung jawab dalam menyelesaikan tugas pekerjaannya.

Menurut Danang Sunyoto (2012:184) bahwa pengembangan karier guru dapat dilakukan melalui dua cara, sebagai berikut:

a. Cara diklat, misalnya melanjutkan studi atau pendidikan guru baik di dalam negeri maupun diluar negeri, memberikan pelatihan baik di dalam organisasi maupun di luar organisasi, memberikan pelatihan sambil bekerja (on the jon traning).

b. Cara non diklat, misalnya memberikan penghargaan kepada guru, memberi sanksi guru mempromosikan guru ke jabatan yang lebih tinggi, merotasi guru ke jabatan lain yang setara dengan jabatan semula.

Pendapat yang sama juga dikemukakan oleh T. Hani Handoko (2008:123) bahwa pemberdayaan guru adalah peningkatan-peningkatan pribadi yang dilakukan seseorang untuk mencapai suatu rencana. Peningkatan-peningkatan pribadi tersebut dapat dilakukan dengan menempuh pendidikan dan pelatihan.Yuniarsih dan Suwatno (2011:134) berpendapat bahwa pemberdayaan guru merupakan pendekatan formal yang digunakan organisasi untuk menjamin bahwa pegawai dengan kualifikasi tepat dan berpengalaman tersedia pada saat dibutuhkan hal tersebut dapat ditemopuh dengan jalur pendidikan dan pelatihan. Kadarisman (2012:325) bependapat, terdapat beberapa pihak yang terlibat dalam pemberdayaan guru a) dorongan dari kepala sekolah sebagai pemimpin pendidikan di sekolah tersebut, b) guru sebagai ujung tombak proses pembelajaran kelas, dan 3) lembaga dalam perencanaan program-program sekolah yang disusun secara bersamasama oleh stakholders sekolah.

Dari pendapat para ahli di atas dapat dapat disimpulkan bahwa pemberdayaan guru adalah langkah-langkah untuk meningkatkan kemampuan guru dalam hal pengajaran dengan tujuan guru tersebut dapat menjalankan tugas, tanggung jawab, dan fungsinya dengan baik dan professional. Peningkatan kemampuan tersebut dapat dilakukan dengan dua cara: a) diklat seperti mendorong guru untuk melanjutkan pendidikan ke jenjang yang lebih tinggi, mengikut sertakan mereka pada pelatihan, work shop, dan sejenisnya, b) non diklat yaitu mempromosikan mereka pada jenjang jabatan yang lebih tinggi sesuai dengan peraturan yang berlaku.

\section{Pendidikan}


Pendidikan merupakan usaha agar manusia dapat mengembangkan potensi dirinya melalui proses pembelajaran dan atau cara lain yang dikenal dan diakui oleh masyarakat dengan tujuan mengembangkan potensi seseorang untuk memiliki kekuatan spiritual, berahlak mulia, cerdas, berpengetahuan, berkepribadian, sehat, cakap, kreatif, berketerampilan untuk hidup mandiri, dan lain sebagainya. Dalam Undang-Undang Dasar Pasal 1 ayat 1 dan 3 disebutkan bahwa setiap warga negara berhak mendapatkan pendidikan dan pemerintah pengusahakan serta menyelenggarakan satu sistem pendidikan nasional yang meningkatkan keimanan, ketakwaan, dan ahlak mulia dalam rangka mencerdaskan kehidupan bangsa sebagaimana yang diataur dalam undangundang. Menurut Kihajar Dewantara (dalam Made Pidarta, 2007:11) pendidikan adalah menuntun segala kekuatan kodrat yang ada pada anak-anak agar mereka sebagai manusia dan sebagai anggota masyarakat mendapat keselamatan dan kebahagiaan yang setinggitingginya”. Menurut Undang-Undang Sistem Pendidikan Nasional pendidikan adalah usaha sadar dan terencana untuk mewujudkan suasana belajar dan proses pembelajaran agar peserta didik secara aktif memiliki kekuatan spiritual keagamaan, pengendalian diri, kecerdasan, ahlak mulia, serta keterampilan yang diperlukan dirinya, masyarakat, bangsa dan negara.

Dalam melaksanakan prinsip penyelenggaraan pendidikan harus sesuai dengan tujuan pendidikan nasional yaitu mengembangkan kemampuan dan membentuk watak serta peradaban bangsa yang bermartabat dalam rangka mencerdaskan kehidupan bangsa, bertujuan untuk berkembangnya potensi peserta didik agar menjadi manusia yang beriman dan bertakwa kepada Tuhan Yang Maha Esa, berakhlak mulia, sehat, berilmu, cakap, kreatif, mandiri, dan menjadi warga negara yang demokratis, serta bertanggung jawab.

Dalam pendidikan sesuai yang diatur dalam undang-undang bahwa jalur pendidikan terbagi menjadi dua, 1) pendidikan formal, dan 2) pendidikan non formal. Di bawah ini akan dijelaskan jalur pendidikan formal sesuai dengan pokok pembahasan di atas. Menurut Undang-undang Sistem Pendidikan Nasional bahwa pendidikan formal adalah jalur pendidikan terstruktur dan berjenjang yang terdiri atas pendidikan dasar, pendidikan menengah, dan pendidikan tinggi.Dikatakan jalur pendidikan formal karena proses pendidikan tersebut diselenggarakan di sekolah secara berjenjang dan berkesinambungan. Sebagai konsekuensinya, yang berhak masuk ke jalur pendidikan 
formal hanyalah mereka yang dalam batas-batas umur masa belajar dan studi. Dalam undang-undang disebutkan bahwa jenjang pendidikan adalah tahapan pendidikan yang ditetapkan berdasarkan tingkat perkembangan peserta didik, tujuan yang akan dicapai, dan kemampuan yang akan dikembangkan. Dalam pendidikan, jenjang pendidikan formal terdiri atas tiga jejang sebagai berikut: a) pendidikan dasar, pendidikan menengah dan pendidikan tinggi

Dari penjelasan di atas dapat disimpulkan bahwa pendidikan merupakan jembatan untuk membangun kehidupan masa kini dan masa depan yang lebih baik dari masa lalu dengan berbagai kemampuan intelektual, kemampuan berkomunikasi, sikap sosial, kepedulian, dan berpartisipasi untuk membangun kehidupan masyarakat dan bangsa yang lebih baik.

\section{Pelatihan}

Pelatihan merupakan salah satu kegiatan utama organisasi yang sangat diperlukan, di mana pelatihan dapat mempengaruhi tingkat produktifitas kerja, prestasi kerja, meningkatkan pengetahuan, dan keterampilan,serta kekurangan dalam kinerja mereka.

Pendapat Siegel L dan Lane I.M, (dalam Marwansyah, 2008:145-155) bahwa pelatihan adalah upaya organisasi yang terencana untuk membantu para karyawannya mempelajari pengetahuan, keterampilan, dan kemampuan yang terkait dengan pekerjaannya agar mereka dapat meningkatkan prestasi kerja.

Pendapat Akram Ridha, (dalam Noor Fuad dan Gofur Ahmad, 2009:68) training atau pelatihan adalah sekumpulan kegiatan yang bertujuan untuk memperbaiki pengetahuan (knowledge) dan keterampilan (skills) seseorang dengan berdasar pada pertimbangan bahwa kegiatan tersebut bisa dipraktikkan dalam pekerjaan.

Pendapat H. John Bernandian dan Joyce E.A Russell, (dalam Faustino Cardoso Gomes, 2001:45) pelatihan adalah setiap usaha untuk memperbaiki performansi pekerja pada suatu pekerjaan tertentu yang sedang menjadi tannggung jawabnya atau suatu pekerjaan yang ada kaitannya dengan pekerjaannya.

Pelatihan berperan penting dalam meningkatkan produktivitas seseorang.Menurut pendapat Laird (Noor Fuad dan Gofur Ahmad, 2009:73) memandang pentingnya pelaksanaan pelatihan atau training bagi organisasi setidaknya berdasarkan tiga alasan sebagai berikut: 
a) Organisasi akan memperoleh output atau keluaran yang optimal dikarenakan setiap pegawai melaksanakan tugas sesuai dengan standar yang diharapkan.

b) Sebelum seorang pegawai dapat melaksanakan pekerjaan sebagaimana mestinya, mereka harus menguasai penggunaan teknologi mutakhir bagi organisasi mereka. Hal ini berarti setiap pegawai dituntut untuk memiliki pengetahuan dan keterampilan yang mendukung pelaksanaan tugas tersebut.

c) Pelatihan merupakan usaha pencapaian teknologi yang membuat seorang pegawai mampu melaksanakan pekerjaan sesuai dengan standar yang diharapkan.

Dari kajian teori di atas dapat disintesiskan bahwa pelatihan meliputi: a) membekali keterampilan guru, b) memperbaiki kelamahan dan kekurangan yang dimiliki guru, c) peningkatan kemampuan, ketermpilan, pengetahuan, disiplin, dan sikap guru, d) mengembangkan kompetensi guru ke arah yang lebih baik.

\section{METODE}

Penelitian ini menggunakan pendekatan kualitatif dan metode yang digunakan studi kasus. Penelitian ini dilaksanakan di Madrasah Ibtidaiyah Al-Ifadah kelurahan dan Penjaringan Jakarta Utara. Adapun waktu pelaksanaan penelitian ini mulai Desember 2016 sampai April 2017. Dalam pengumpulan data, peneliti menggunakan beberapa teknik yaitu: a) observasi yaitu pengamatan secara mendalam terhadap objek penelitian, b) wawancara yaitu peneliti mewawancarai kepala sekolah sebagai key informan atau sumber utama, guru senior, dan tenaga kependidikan, c) angket daftar pertanyaan yang diberikan kepada stakeholders atau pelaku pendidikan di sekolah tersebut.

\section{HASIL DAN PEMBAHASAN}

Dalam penelitian ini, peneliti menemukan dua langkah dalam pemberdayaan guru di MI Al-Ifadah Penjaringan Jakarta Utara.Dua langkah tersebut adalah yaitu pendidikan dan pelatihan. Kepala Madrasah Ibtidaiyah (MI) Al-Ifadah selaku kepala pendidikan di sekolah tersebut selalu menekankan kepada guru akan pentingnya pendidikan. Hal tersebut dapat dilihat sejak berdirinya Madrasah Ibtidaiyah (MI) Al-Ifadah hampir 90\% guru-guru yang mengajar di sekolah tersebut belum sarjana strata satu (S1). Melalui program kerjasama dengan pendidikan tinggi, kepala sekolah berhasil mendorong guruguru dalam menyelesaikan pendidikan strata satu (S1). 
Pendidikan formal dapat berpengaruh terhadap output pendidikan, jenjang pendidikan formal merupakan salah satu langkah dalam pemberdayaan guru. Hal ini sesuai dengan pendapat Robert N Luissier (2008:108) “empowerment is the process of gaining skill, experience, and education to achieve career objectives.

Pendapat yang sama juga dikemukakan Danang Sunyoto (2012:184) bahwa, “pemberdayaan guru dapat dilakukan melalui dua cara sebagai berikut: 1) cara diklat, seperti: a) melanjutkan studi atau pendidikan pegawai baik di dalam negeri maupun diluar negeri, b) memberikan pelatihan baik di dalam organisasi maupun di luar organisasi, c) memberikan pelatihan sambil bekerja (on the jon traning), 2) cara non diklat, contoh: a) memberikan penghargaan kepada pegawai, b) memberi sanksi pegawai, c) mempromosikan pegawai ke jabatan yang lebih tinggi, d) merotasi pegawai ke jabatan lain yang setara dengan jabatan semula.

Selain pendidikan, pelatihan memiliki peran penting dalam pemberdayaan guru dan dapat meningkatkan produktifitas kerja, prestasi kerja, meningkatkan pengetahuan, dan keterampilan guru. Temuan tersebut sesuai dengan teori yang dikemukakan oleh Lloyd L. Byars dan Leslie W. Rue (2008:10) “training is learning process that involves the acquisition of knowledge, skill and abilities (KAS) necessary to successfully perform $a$ job”.Pelatihan adalah pembelajaran yang melibatkan kemampuan-kemampuan untuk mendapatkan pengetahuan, keterampilan, dan kemampuan diri dengan tujuan mensukseskan pelaksanaan suatu pekerjaan. Pendapat yang sama juga dikemukakan oleh Robert L. Mathis dan John H. Jackson (2011:205)bahwa ”training is the process whereby people acquire capabilities to perform jobs”.Pelatihan adalah proses yang mana seseorang memperoleh kemampuan untuk melakukan atau menyelesaikan tugas-tugasnya dengan baik.

Terdapat dua teknik pelaksanaan pelatihan di Madrasah Ibtidaiyah (MI) AlIfadah yaitu internal dan eksternal. Temuan tersebut sesuai dengan teori yang dikemukakan oleh Goetsch dan Davis (2010:262) bahwa "training can be provided inhouse: through corporate-owned education and training facilitaties; in conjuction with colleges, universities, and pofessional organizations; or via satellite downlinks.”Sebuah organisasi dapat memberikan pelatihan secara internal atau dikenal dengan in-house training. In house training dapat dilakukan di tempat sendiri dengan bekerja sama dengan 
universitas, lembaga profesional yang menyediakan jasa pendidikan dan pelatihan atau dapat melalui pembelajaran jarak jauh.

\section{SIMPULAN}

Berdasarkan hasil temuan dan pembahasan temuan penelitian yang dikemukakan pada pembahasan di atas dapat disimpulkan bahwa pemberdayaan guru melalui peningkatan pendidikan guru di MI Al-Ifadah sangat diperhatikan oleh kepala sekolah. Hal tersebut dapat dilihat adanya kerja sama antara pihak sekolah dengan perguruan tinggi swasta (PTS) dalam penyelesaian program strata satu (S1).Tidak hanya berhenti di strata satu, guru-guru didorong untuk melanjutkan pendidikan tinggi program strata dua (S2) baik di PTN maupun PTS di wilayah Jakarta dan sekitarnya.Selain pemberdayaan guru melalui peningkatan pendidikan, pemberdayaan guru di Madrasah Ibtidaiyah (MI) Al-Ifadah juga dilakukan melalui pelatihan yang berkala baik pelatihan internal maupun ekternal.

\section{SARAN}

Penelitian ini perlu ditindak lanjuti agar pendidikan tingkat sekolah dasar dan setingkatnya lebih meningkatkan pemberdayaan guru melalu pendidikan formal dan pelatihan sehingga kemampuan guru dalam menjalankan fungsi, tugas, dan tanggung jawabnya sebagai pendidikan dapat dilaksanakan secara optimal sehingga output atau luarannya adalah menghasilkan siswa/siswi yang cerdas, kompeten, dan berkarakter.

\section{DAFTAR PUSTAKA}

Anthony, William P., Perrewe, Pamela L., dan Kamar, K Mihele. 2008. Human Resoure Management.Boston : MGraw-Hill/Irwin,

ArdosoGomes, Faustino. 2003. Manajemen Sumber Daya Manusia. Yogyakarta: Andi Offset,

Astetter, William B. 1981. The Personnel Funtion in Eduational Administration. New York :Mamillan Publishing Company.

Byars, LIoyd L., dan Rue, Leslie W., 2008. Human Resoure Management, Ninth Edition. Boston : MGraw-Hill/Irwin. 
Fuad, Noor dan Ahmad, Gofur. 2009. Integrated Human Resoures Development Berdasarkan Pendekatan B-HRM, BT dan PD. Jakarta: Grasindo.

Hasibuan, Malayu S.P. 2011. Manajemen Sumber Daya Manusia, Edisi Revisi. Jakarta: Bumi Aksara.

Kadarisman, M. 2012. Manajemen Pengembangan Sumber Daya Manusia. (Depok: Rajagrafindo Persaja.

Mathis, Robert L. dan Jakson, John H. 2011. Human Resoure Management. Australia: South-Western engage Learning.

Noe, Raymond A., Hollenbek, John R., Gerhart, Barry., Wright, Patrik M. 2003. Human Resoure Management. Boston : MGraw-Hill Higher Eduation.

Peraturan Pemerintah Republik Indonesia Nomor 19 Tahun 2005 tentang Standar Nasional Pendidikan.

Peraturan Menteri Pendidikan dan Kebudayaan Republik Indonesia Nomor 70 Tahun 2013 tentang Kerangka Dasar dan Struktur Kurikulum Sekolah Menengah Kejuruan dan Madrasah Aliyah Kejuruan.

Pidarta, Made. 2007. Landasan Pendidikan, Stimulus Ilmu Pendidikan Bercorak Indonesia. Jakarta: Reneka Cipta.

Rowley, Chris dan Jackson, Keith. 2012. Human Resources Management: The Key Conceps, penerjemah Elviyola Pawan. Jakarta: Rajagrafindo Persada.

Suwatno, dan Juni Priansa, Donni. 2011. Manajemen SDM dalam Organisai Publik dan Bisnis. Bandung: Alfabeta.

Suyoto, Danang. 2012. Manajemen Sumber Daya Manusia Dilengkapi dengan Budaya Organisasi, Pengembangan Organisasi dan Outsouring. Yogyakarta: enter for Aademi Publishing Servie.

Undang-Undang Nomor 20 Tahun 2003 tentang Sistem Pendidikan Nasional.

Werther, William B, dan Jr. Keith Davis. 1993. Human Resources Management.USA: McGraw-Hills. 